\title{
Gas phase substitution of halobenzenes by methylamine and dimethylamine via radical cations*
}

\author{
Detlef Thölmann and Hans-Friedrich Grützmacher \\ Lehrstuhl I Organische Chemie, Fakultät für Chemie, Universität Bielefeld, Postfach 8640 , \\ Universitätstrasse, W-4800 Bielefeld (Germany)
}

(First received 21 January 1992; in final form 6 March 1992)

\begin{abstract}
The reactions of the radical cations of the halobenzenes $\mathrm{C}_{6} \mathrm{H}_{5} \mathrm{X}^{+}(\mathrm{X}=\mathrm{Cl}, \mathrm{Br}, \mathrm{I})$, the isomeric dichlorobenzenes and the isomeric chloroiodobenzenes with $\mathrm{CH}_{3} \mathrm{NH}_{2}$ as well as the reactions of the radical cations $\mathrm{CH}_{3} \mathrm{NH}_{2}^{+}$and $\left(\mathrm{CH}_{3}\right)_{2} \mathrm{NH}^{+}$with the above neutral halobenzenes were studied by Fourier transform ion cyclotron resonance spectrometry. In all cases the substitution of a halogen substituent by $\mathbf{R}_{2} \mathrm{NH}^{+}\left(\mathrm{R}=\mathrm{H}, \mathrm{CH}_{3}\right.$ ) was observed besides charge exchange. The substitution of halobenzene radical cation by $\mathrm{CH}_{3} \mathrm{NH}_{2}$ is always fast (the reaction efficiency (eff ${ }_{\text {subst }}$ ) being greater than $28 \%$ ) compared to the reaction with $\mathrm{NH}_{3}$ studied before, but exhibits principally the same dependence on the nature and position of the halogen substituent as the latter reaction. The substitution of neutral halobenzenes, where the ionization energy of the halobenzene is greater than the ionization energy of methylamine, by $\mathrm{CH}_{3} \mathrm{NH}_{2}^{+}$ is also fast ( $\left(\mathrm{ff}_{\text {subst }}>50 \%\right.$ ) and is not much influenced by the structure of the halobenzene. In contrast, the rate of substitution of all halohenzenes by $\left(\mathrm{CH}_{3}\right)_{2} \mathrm{NH}^{+}$is small (eff subst $<14 \%$ ), increases with the halogen lost in the series $\mathrm{Cl}<\mathrm{Br}<\mathrm{I}$, and exhibits a distinct orientation effect for dihalobenzenes, the meta isomer being least reactive. These experimental results are discussed using thermochemical data from the literature and the curve crossing model of Shaik and Pross. The results are consistently rationalized for the reaction of ionized halobenzenes with neutral amines as well as the reaction of neutral halobenzenes with ionized amines by a mechanism involving addition to the aromatic system, rearrangement of the intermediate distonic ion to an ipso-substituted isomer, and dissociation of the intermediate by loss of halogen. However, the rate-determining step of this mechanism depends on the substrates involved, and this structural dependence of the reactions can be understood by the curve crossing model.
\end{abstract}

Keywords: FT-ICR; gas phase substitution; halobenzenes; methylamine; radical cations.

\section{INTRODUCTION}

The chemistry of organic radical cations is fascinating, both with respect to their possible use in organic synthesis and for a theoretical analysis of their reactivity. Radical cations have been proposed as reactive intermediates to explain electrochemically initiated or photostimulated substitution reactions

Correspondence to: H.-F. Grützmacher, Lehrstuhl I Organische Chemie, Fakultät für Chemic, Universität Bielefeld, Postfach 100131, Universitätsstrasse, W-4800 Bielefeld, Germany. * Dedicated to Professor Charles H. DePuy on the occasion of his 65th birthday. 
of olefinic and aromatic compounds [1]. Another interesting reaction of alkene radical cations is the cycloaddition to alkadienes [2], for which Bauld and co-workers have demonstrated [2(a),(b)] an efficient catalysis by amine radical cations acting as a one-electron oxidant of the alkene. This effect has been explained by orbital correlations [2(c),(d)] and has been coined as "hole catalysis" because of the favourable effect of the electron "hole" in the single occupied molecular orbital of the radical cation. A recent example of this "hole catalysis" is the fast oxidation of styrene radical cations in solution to phenyl-oxirane by a variety of simple oxygen donors [3]. Thus, organic radical cations are expected to be valuable reactive intermediates for organic reactions. In particular, one would expect an instantaneous reaction of electron-deficient organic radical cations with electron-rich nucleophiles, resulting in a "hole catalysis" [3] of nucleophilic substitution. However, a treatment of the reactions of olefinic and aromatic radical cations with nucleophiles by the configuration mixing or curve crossing model of Shaik and Pross [4] predicts larger activation energies for these reactions in comparison with reactions of nucleophiles and carbenium ion of the same redox properties as the nucleophile-radical cation combination. In this model the activation energy of a reaction is related to the so-called initial energy gap, $\Delta E_{\mathrm{G}}$, representing the energy difference between an excited state of the reactants with the electron configuration of the products and the ground state of the reactants. The relevant excited state for the reaction of unsaturated radical cations with nucleophiles arises from the ground state by a charge exchange and a decoupling of an electron pair of the unsaturated compound. Thus a double-excited state of the reactants is involved. In some cases the double excitation leads to a large $\Delta E_{\mathrm{G}}$ and consequently to a large activation barrier of the process. However, in other cases, e.g. in the reaction of the ketene radical cation with ammonia, the $\Delta E_{\mathrm{G}}$ is small despitc the double excitation, and the barrier is accordingly small [4(c)]. The $\Delta E_{\mathrm{G}}$ quantity is the origin of why there exists a barrier at all, be this large or small. It should be noted, however, that while the barrier is gauged by $\Delta E_{\mathrm{G}}$ this is not the only factor which affects the barrier height. There are other factors, such as the reaction energy and the delocalization properties of the excited states [4(b)], which scale the size of the barrier for any given value of $\Delta E_{\mathrm{G}}$.

Simple organic radical cations are difficult to handle for mechanistic studies in solution because of their high oxidation potential and high reactivity. In contrast, radical cations in the (diluted) gas phase are easily prepared and investigated by mass spectrometric techniques. In fact, the addition of certain alkene radical cations to alkenes and alkadienes in the gas phase has been known and used for some time [5] for the analysis of alkenes by chemical ionization mass spectrometry. An ion cyclotron resonance study of the addition reactions of alkene radical cations to butadiene [6] revealed 
that these processes are rather fast, contrary to the theoretical prediction. Similarly, the reaction of the radical cations of cyclopropene [7] and of ketene [8], respectively, with ammonia is fast, again apparently contradicting the theoretical prognosis. This latter contradiction has been recently resolved by Shaik and Pross [4(c)] by showing that the small activation barrier coincides in fact with a small $\Delta E_{\mathrm{G}}$.

Recently, we have studied the nucleophilic substitution reactions of radical cations of dichloroethenes [9] and of monohalogenated and dihalogenated benzenes [10] with ammonia by Fourier transform ion cyclotron resonance (FT-ICR) spectrometry. The reactions of the dichloroethene radical cations with $\mathrm{NH}_{3}$ are again fast exhibiting reaction efficiencies greater than $50 \%$, while the substitution of the halobenzene radical cations by $\mathrm{NH}_{3}$ is slow with reaction efficiencies less than $15 \%$. A detailed analysis of the kinetics of these ion/molecule reactions shows $[9,10(b)]$ that these substitution reactions proceed by an addition/elimination mechanism involving at least two reaction steps (Scheme 1). In the case of the aromatic radical cations the addition of the nuecleophile $\mathrm{NH}_{3}$ is rate determining, demanding the participation of a double-excited reactant state [4] according to the curve crossing model. Thus, at least the reaction of halobenzene radical cations with $\mathrm{NH}_{3}$ can be understood by using the model of Shaik and Pross. This model predicts inter alia that the rate of the addition of the nucleophile to the aromatic radical cation decreases with an increasing ionization energy difference of the reactants which is positively observed.

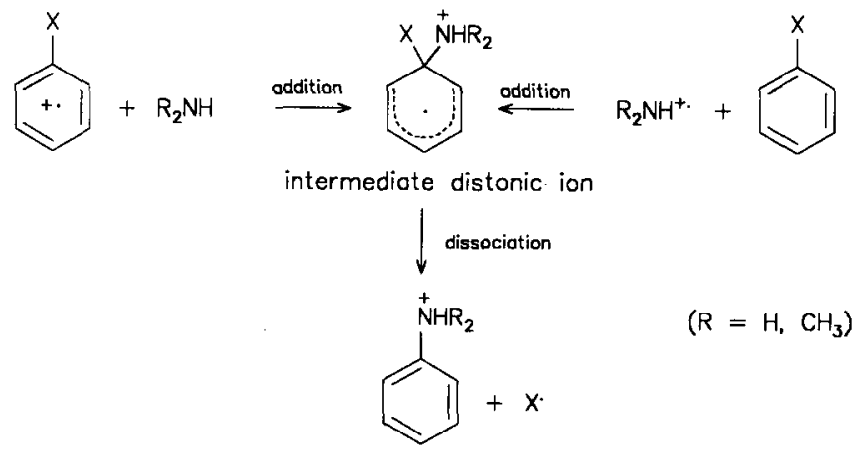

Scheme 1.

Another interesting feature of the substitution of dihalogenated benzene radical cations by $\mathrm{NH}_{3}$ is the rather surprising effect of the substitution pattern on the reaction rate. Both for homo- and hetero-disubstituted dihalobenzene radical cations the reaction efficiency decreases distinctly in the order ortho $>$ meta $>>$ para. This order of reactivity cannot be explained by a variation in the ionization energy, but follows the magnitude of the dipole 
moment of the neutral precursor of the aromatic radical cations. Within the framework of the curve crossing model this orientation effect is explained by a stabilization of the relevant excited state of the reactants by ion/dipole interaction [10(a)] reducing $\Delta E_{\mathrm{G}}$ and the activation energy of the addition step. This interpretation is analogous to that of solvent effects on polar reactions, and an effect due to different electrostatic stabilization of an excited state and the ground state has subsequently also been discussed for electrochemical reactions of organic radical cations [11] in solution.

According to the curve crossing model the addition of an ionized nucleophile to a neutral halobenzene should be more facile than the reaction with a reversed charge distribution between the reactants, although the same distonic ion is generated by the addition step (Scheme 1). While in the latter case $\Delta E_{\mathrm{G}}$ is determined by a double-excited state of the reactants, i.e. a state formed by charge exchange and corresponding to a triplet benzene [12], in the former reaction $\Delta E_{\mathrm{G}}$ arises only by the decoupling of an electron pair in the neutral benzene, i.e. the triplet state.

As a consequence, the curve crossing model predicts a rather peculiar and interesting dependence of the reaction efficiency on the ionization energy (IE) difference between the halobenzene and the nucleophile. Reducing the IE of the nucleophile decreases $\Delta E_{\mathrm{G}}$ and results in an increase in the reaction rate of an ionized benzene derivative with a neutral nucleophile until the IE of the nucleophile drops below that of the benzene derivative. In this case, only an exothermic charge exchange between the nucleophile and the aromatic radical cation can be observed if this ion is injected into the FT-ICR cell filled with the gaseous nucleophile [13]. However, filling the cell with the neutral benzene derivative and injecting the ionized nucleophile should result in a fast reaction giving rise to substitution products as before (Scheme 1). The effect of a further decrease in the IE of the nucleophile on the reaction rate is difficult to predict, however, because $\Delta E_{\mathrm{G}}$ depends only on the singlet-triplet separation of the halogenated benzene. In addition, the effect of the substitution pattern of dihalogenated benzenes on the rate of the addition step is expected to change with the different charge distribution between the reactants. The reactivity order ortho $>$ meta $>>$ para is only expected for the reaction of the aromatic radical cations with a neutral nucleophile. In the case of the reversed charge distribution between the reactants the charge must not migrate from the reacting radical cation to the aromatic ring (Scheme 1). Hence, the origin of this orientation effect, the change in the electrostatic interaction between the two reactants in the ground state and excited state, is absent. It should be remembered that of course the dipole moment of the neutral reactant affects the collision rate during an ion/molecule reaction, and hence the rates of the positional isomers of a dihalobenzene with an ionized nucleophile have to differ because of the different dipole moments of the 
isomers, but this effect is taken into account by determining the reaction efficiency (eff) according to the capture rate by parameterized trajectory calculations [14]. Finally, the decrease of the activation energy of the addition step by decreasing $\Delta E_{\mathrm{G}}$ may eliminate the addition as the rate-determining step of the total substitution reaction. As a consequence it may be possible to detect structural effects of the reactants on the reaction steps following the addition step. The study of the reactions of dichloroethenes [9] has indicated that indeed the reaction mechanism may include rearrangements of the distonic ion formed by the addition.

The ionization energy of methylamine of $8.97 \mathrm{eV}$ [15] is close to the ionization energies of monohalobenzenes and dihalobenzenes [15], while that of dimethylamine of $8.23 \mathrm{eV} \mathrm{[15]} \mathrm{is} \mathrm{distinctly} \mathrm{below} \mathrm{that} \mathrm{of} \mathrm{the} \mathrm{halobenzenes.}$ Thus an FT-ICR study of the rates of the substitution reactions of methylamine and dimethylamine, respectively, and selected halogenated benzenes via radical cations using different charge distributions between the reactants may give more interesting information about the mechanism of the aromatic substitution reactions by radical cations. The results show that the curve crossing model of Shaik and Pross predicts qualitatively the effects observed for these reactions, but that in the case of a fast addition step the rate of the total reaction is also controlled by the reaction thermochemistry.

\section{EXPERIMENTAL}

Pure chlorobenzene (1), bromobenzene (2), iodobenzene (3), 1,2-, 1,3- and 1,4-dichlorobenzene $(4,5$, and 6 , respectively) are commercially available and were used without further purification. The 1,2-, 1,3- and 1,4-chloroiodobenzenes ( 7,8 and 9 respectively) were prepared by diazotization and iodination [16] of the corresponding chloroanilines, which are commercially available. The isomeric purity of all compounds was verified by gas chromatography and was better than $99 \%$. Methylamine (Merck, 97\%) and dimethylamine (Merck, 99\%) were used without further purification.

The FT-ICR measurements were performed with a Spectrospin CMS 47X FT-ICR instrument [17] equipped with a $4.7 \mathrm{~T}$ superconducting magnet, a 24 bits/128 k-word ASPECT 3000 computer, a cylindrical analyser cell with a diameter of $6 \mathrm{~cm}$ and a length of $6 \mathrm{~cm}$, and an external ion source [18] for electron impact and chemical ionization.

Ions were generated in the external ion source by electron impact ionization $(15-20 \mathrm{eV})$ from the corresponding neutral halogenated benzenes, methylamine and dimethylamine respectively, and were transferred into the ICR analyser cell containing the appropriate neutral reagent at a constant pressure. The trapping voltages of the front and back trapping plates were $1.0 \mathrm{~V}$, the d.c. voltages at the excitation plates and at the detection plates were 
kept at $0 \pm 0.1 \mathrm{~V}$. The selection of the radical cation for the reaction to be studied was achieved by "broad band" chirp ejection (frequency sweep ejection). The excitation voltage was attenuated by an attenuator of six, corresponding to $88 \mathrm{~V}_{\mathrm{p}-\mathrm{p}}$. All ions below $\mathrm{m} / \mathrm{z} 50$ and the isotopomers of the selected radical cation containing ${ }^{2} \mathrm{H},{ }^{13} \mathrm{C},{ }^{37} \mathrm{Cl}$ and ${ }^{81} \mathrm{Br}$ isotopes were ejected by fixed frequency r.f. pulses ("single shots") of $14 \mathrm{~V}_{\mathrm{p}-\mathrm{p}}$, attenuator 22 , and of $15 \mathrm{~ms}$ duration.

Special care was taken to remove any kinetic energy from the selected radical cations stemming from the transfer process and/or the ejection procedure for the other ions from the ICR cell. The collisional "cooling" of the isolated ions was accomplished by a short pulse of argon admitted to the ICR cell by a pulsed valve (opening time $15 \mathrm{~ms}$ ) prior to the reaction. After a delay time of $500 \mathrm{~ms}$ for removing the argon from the cell, any fragment ions formed in the mean time were ejected again by single shots $\left(14 \mathrm{~V}_{\mathrm{p}-\mathrm{p}}, 1.5 \mathrm{~ms}\right)$, thus avoiding a re-excitation of the selected ions by the ejection process.

Methylamine and dimethylamine, respectively, as the neutral reactants, were introduced continuously from a reservoir into the ICR using a leak valve to establish a (calibrated) constant pressure between $5 \times 10^{-8}$ and $1 \times 10^{-6}$ mbar. The halogenated benzenes as neutral reactants were degassed and introduced from a gently heated sample bulb into the ICR cell by a leak valve to establish a constant pressure ranging from $1 \times 10^{-8}$ to $2 \times 10^{-7}$. The purity of the neutral reactant in the ICR cell was monitored by the mass spectrum obtained by using the internal ionization mode of the CMS $47 \mathrm{X}$ spectrometer.

The pressure readings of the ionization gauge close to the high vacuum pump for the ICR cell were calibrated by rate measurements of the reactions $\mathrm{CH}_{4}^{++}+\mathrm{CH}_{4} \rightarrow \mathrm{CH}_{5}^{+}+\cdot \mathrm{CH}_{3} \quad\left(k=1.5 \times 10^{-9} \mathrm{~cm}^{3}\right.$ molecule $\left.{ }^{-1} \mathrm{~s}^{-1} \quad[19]\right)$, $\mathrm{NH}_{3}^{+}+\mathrm{NH}_{3} \rightarrow \mathrm{NH}_{4}^{+}+\cdot \mathrm{NH}_{2}\left(k=2.2 \times 10^{-9} \mathrm{~cm}^{3}\right.$ molecule ${ }^{-1} \mathrm{~s}^{-1}$ [20]), and $\mathrm{CH}_{3} \mathrm{NH}_{2}^{+}+\mathrm{CH}_{3} \mathrm{NH}_{2} \rightarrow \mathrm{CH}_{3} \mathrm{NH}_{3}^{+}+\mathrm{CH}_{3} \mathrm{NH} \cdot\left(k=1.8 \times 10^{-9} \mathrm{~cm}^{3}\right.$ molecule $^{-1} \mathrm{~s}^{-1}$ [21]). This calibration was regularly repeated throughout this work. The sensitivity of the ionization gauge towards the gases used was determined by a standard procedure [22].

The FT-ICR mass spectra were obtained with $32 \mathrm{~K}$ or $64 \mathrm{~K}$ data for about 20 different reaction times, monitoring each reaction up to at least $95 \%$ conversion. After an exponential multiplication of the time-domain signal and Fourier transformation, the ion intensities of the magnitude spectra were normalized with respect to the total ion intensity at that reaction time. To ensure a correct measurement of the ion abundances, the variation of the absolute total ion intensity with reaction time was analysed and compared with the corresponding variation of trapped unreactive ions at the corresponding delay times ("trapping characteristics") as discussed in detail elsewhere [10]. Pseudo-first-order kinetics were obtained from the exponential 
decaying intensity of the reacting radical cations, and taking into account the constant pressure of the neutral reagent, the bimolecular rate constant was calculated using $300 \mathrm{~K}$ as the temperature of the gas within the ICR cell. In the case of competing pseudo-first-order reactions the branching ratio $k_{1} / k_{2}$ was obtained directly from the ratio of the abundances of the corresponding product ions, skipping the first points corresponding to the first $10-20 \%$ of the total reaction time during which non-ideal behaviour is observed. The branching ratio was constant throughout the later reaction. In the case of additional consecutive reactions, however, this method cannot be used, and the unimolecular rate constants of the initial reactions were obtained from the slopes of the ion intensity curves of the product ions of the competing reactions extrapolated to zero reaction time. The sum of the individual rate constants of the competing reactions obtained by this method has to be equal to the rate constant $k_{\text {total }}$ determined from the decay of the reactant ion. This has been used to control the correct evaluation of the individual rate constants. Nevertheless, the method of the initial slopes is not very precise and is only used to estimate the branching ratio. Then, this ratio was used to calculate the individual rate constants from the $k_{\text {total }}$ more accurately measured from the decay of the reactant ion.

\section{RESULTS}
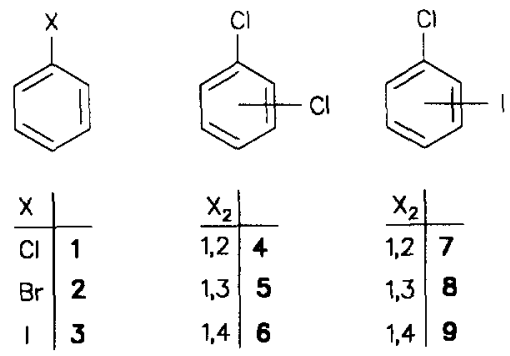

Scheme 2.

Reactions of halobenzene and dihalobenzene radical cations with methylamine

The radical cations of the halobenzenes 1,2 , and 3 (Scheme 2) react easily with $\mathrm{CH}_{3} \mathrm{NH}_{2}$ by substitution of a halogen (reaction (1)) and charge exchange (reaction (2)) yielding primarily $\mathrm{CH}_{3} \mathrm{NH}_{2}^{+}, \mathrm{m} / z$ 31, and $\mathrm{N}$-methylanilinium ions, $m / z 108$, respectively, but not directly by forming $\mathrm{CH}_{3} \mathrm{NH}_{3}^{+}$.

$$
\begin{aligned}
\mathrm{C}_{6} \mathrm{H}_{5} \mathrm{X}^{\cdot+}+\mathrm{H}_{2} \mathrm{NCH}_{3} & \rightarrow \mathrm{C}_{6} \mathrm{H}_{5} \mathrm{NH}_{2} \mathrm{CH}_{3}^{+}+\mathrm{X} \cdot \\
& \rightarrow \mathrm{C}_{6} \mathrm{H}_{5} \mathrm{X}+\mathrm{CH}_{3} \mathrm{NH}_{2}^{+}
\end{aligned}
$$

$\mathrm{CH}_{3} \mathrm{NH}_{2}^{+}$reacts quickly with excess $\mathrm{CH}_{3} \mathrm{NH}_{2}$ by hydrogen abstraction, 

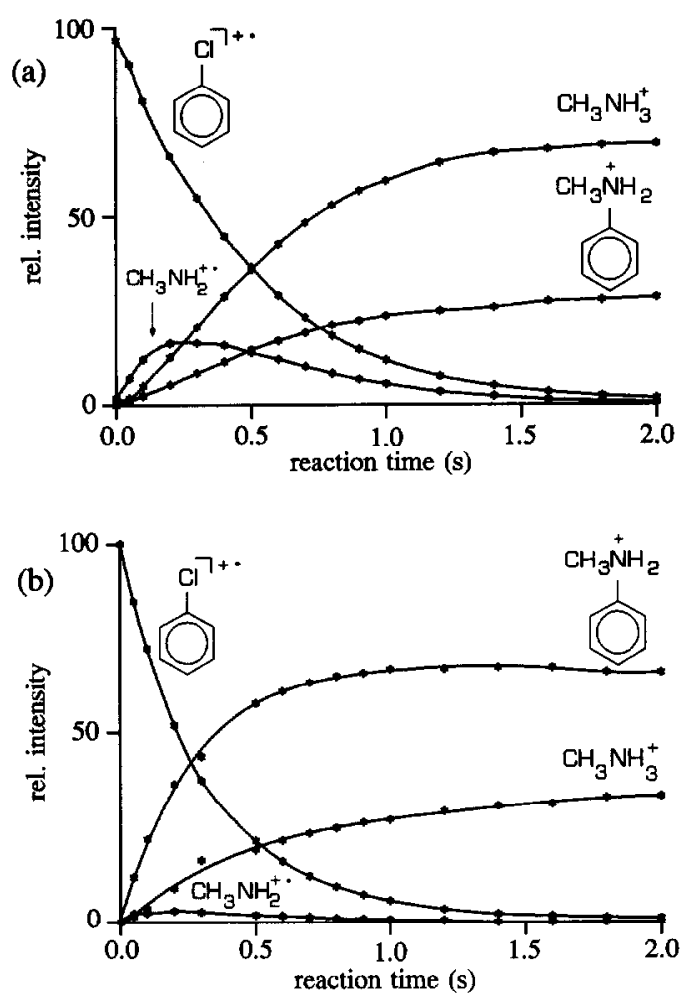

Fig. 1. Ion intensity vs. reaction time for the reaction of $1^{-+}$with $\mathrm{CH}_{3} \mathrm{NH}_{2}$ (a) without collisional deactivation, (b) with collisional deactivation by argon pressure pulse.

giving eventually $\mathrm{CH}_{3} \mathrm{NH}_{3}^{+}, m / z 32$. The ion intensity curves for the reaction $\mathbf{1}^{+}$are shown in Fig. 1 as a typical example.

The bimolecular rate constants $k_{\text {total }}$ and $k_{\text {subst }}$ for the disappearance of the halobenzene radical cation and for the appearance of the substitution product, respectively, are listed in Table 2 . Included are the reaction efficiencies which were calculated by $\operatorname{eff}_{\text {total }}=k_{\text {total }} / k_{\text {cap }}$ and eff $_{\text {subst }}=k_{\text {subst }} / k_{\text {cap }}$, evaluating $k_{\text {cap }}$ according to Su and Chesnavich [14] with the relevant dipole moments and polarizabilities shown in Table 1. The IE of methylamine $(8.97 \mathrm{eV} \mathrm{[15])}$ and those of $1(9.06 \mathrm{eV}$ [15]) and 2 (8.98 eV [15]) show that in these cases a charge exchange from the aromatic radical cation is more or less thermoneutral, while a charge exchange of the radical cation of $3(8.69 \mathrm{eV}$ [15]) is slightly endothermic. As a consequence the branching between charge exchange (1) and substitution (2) is very sensitive to any excess kinetic energy of the halobenzene radical cations. The data of Table 2 were only obtained by a very careful "cooling" of the halobenzene radical cations in the ICR cell. Otherwise charge exchange to ions $m / z 31$ and subsequent formation of ions $\mathrm{m} / \mathrm{z} 32$ is the main process. This is seen from Fig. 1 which shows the results 


\section{TABLE 1}

Ion/molecule capture rates [14], $k_{\text {cap }}$, calculated from dipole moments, $\mu_{\mathrm{D}}$, and polarizabilities, $\alpha$

\begin{tabular}{|c|c|c|c|c|}
\hline \multirow[t]{2}{*}{ Reaction } & \multicolumn{2}{|l|}{ Neutral } & \multirow{2}{*}{$\begin{array}{l}k_{\text {cap }} \\
\left(10^{9} \mathrm{~cm}^{3} \text { molecule }\right.\end{array}$} & \multirow{2}{*}{$\left.{ }^{1} s^{1}\right)$} \\
\hline & $\alpha\left(\AA^{3}\right)$ & $\mu_{\mathrm{D}}(\mathrm{D})$ & & \\
\hline $\begin{array}{l}\mathrm{C}_{6} \mathrm{H}_{3} \mathrm{Cl}^{\cdot+}+\mathrm{NH}_{3} \\
\mathrm{C}_{6} \mathrm{H}_{5} \mathrm{Br}^{++}+\mathrm{NH}_{3} \\
\mathrm{C}_{6} \mathrm{H}_{5} \mathrm{I}^{\cdot+}+\mathrm{NH}_{3} \\
\mathrm{C}_{6} \mathrm{H}_{4} \mathrm{Cl}_{2}^{++}+\mathrm{NH}_{3} \\
\mathrm{C}_{6} \mathrm{H}_{4} \mathrm{Br}_{2}^{++}+\mathrm{NH}_{3} \\
\mathrm{C}_{6} \mathrm{H}_{4} \mathrm{BrCl}^{+}+\mathrm{NH}_{3} \\
\mathrm{C}_{6} \mathrm{H}_{4} \mathrm{ClF}^{++}+\mathrm{NH}_{3} \\
\mathrm{C}_{6} \mathrm{H}_{4} \mathrm{BrF}^{\cdot+}+\mathrm{NH}_{3} \\
\mathrm{C}_{6} \mathrm{H}_{4} \mathrm{ClI}^{++}+\mathrm{NH}_{3}\end{array}$ & $2.26[23(a)]$ & $1.47[23(\mathrm{a})]$ & $\begin{array}{l}2.05 \\
2.01 \\
1.99 \\
2.02 \\
1.98 \\
2.00 \\
2.03 \\
2.00 \\
1.98\end{array}$ & . \\
\hline $\begin{array}{l}\mathrm{C}_{6} \mathrm{H}_{5} \mathrm{Cl}^{++}+\mathrm{CH}_{3} \mathrm{NH}_{2} \\
\mathrm{C}_{6} \mathrm{H}_{5} \mathrm{Br}^{+}+\mathrm{CH}_{3} \mathrm{NH}_{2} \\
\mathrm{C}_{6} \mathrm{H}_{5} \mathrm{I}^{++}+\mathrm{CH}_{3} \mathrm{NH}_{2} \\
\mathrm{C}_{6} \mathrm{H}_{4} \mathrm{Cl}_{2}^{++}+\mathrm{CH}_{3} \mathrm{NH}_{2} \\
\mathrm{C}_{6} \mathrm{H}_{4} \mathrm{ClI}^{\cdot+}+\mathrm{CH}_{3} \mathrm{NH}_{2}\end{array}$ & $4.1[23(b)]$ & $1.33[23(\mathrm{c})]$ & $\begin{array}{l}1.64 \\
1.59 \\
1.56 \\
1.60 \\
1.55\end{array}$ & \\
\hline $\begin{array}{l}\mathrm{CH}_{3} \mathrm{NH}_{2}^{\cdot+}+\mathrm{C}_{6} \mathrm{H}_{5} \mathrm{Cl} \\
\mathrm{CH}_{3} \mathrm{NH}_{2}^{+}+\mathrm{C}_{6} \mathrm{H}_{5} \mathrm{Br} \\
\mathrm{CH}_{3} \mathrm{NH}_{2}^{+}+1,2-\mathrm{C}_{6} \mathrm{H}_{4} \mathrm{Cl}_{2} \\
\mathrm{CH}_{3} \mathrm{NH}_{2}^{+}+1,3-\mathrm{C}_{6} \mathrm{H}_{4} \mathrm{Cl}_{2} \\
\mathrm{CH}_{3} \mathrm{NH}_{2}^{+}+1,4-\mathrm{C}_{6} \mathrm{H}_{4} \mathrm{Cl}_{2}\end{array}$ & $\begin{array}{l}12.3[23(\mathrm{~d})] \\
13.6[23(\mathrm{~d})] \\
14.2[23(\mathrm{f})] \\
14.2[23(\mathrm{f})] \\
14.5[23(\mathrm{f})]\end{array}$ & $\begin{array}{l}1.69[23(\mathrm{e})] \\
1.70[23(\mathrm{e})] \\
2.54[23(\mathrm{c})] \\
1.72[23(\mathrm{c})] \\
0.0[23(\mathrm{c})]\end{array}$ & $\begin{array}{l}2.38 \\
2.38 \\
3.03 \\
2.43 \\
1.76\end{array}$ & \\
\hline $\begin{array}{l}\left(\mathrm{CH}_{3}\right)_{2} \mathrm{NH}^{\cdot+}+\mathrm{C}_{6} \mathrm{H}_{5} \mathrm{Cl} \\
\left(\mathrm{CH}_{3}\right)_{2} \mathrm{NH}^{\cdot+}+\mathrm{C}_{6} \mathrm{H}_{5} \mathrm{Br} \\
\left(\mathrm{CH}_{3}\right)_{2} \mathrm{NH}^{-+}+\mathrm{C}_{6} \mathrm{H}_{5} \mathrm{I} \\
\left(\mathrm{CH}_{3}\right)_{2} \mathrm{NH}^{\cdot+}+1,2-\mathrm{C}_{6} \mathrm{H}_{4} \mathrm{Cl}_{2} \\
\left(\mathrm{CH}_{3}\right)_{2} \mathrm{NH}^{\cdot+}+1,3-\mathrm{C}_{6} \mathrm{H}_{4} \mathrm{Cl}_{2} \\
\left(\mathrm{CH}_{3}\right)_{2} \mathrm{NH}^{\cdot+}+1,4-\mathrm{C}_{6} \mathrm{H}_{4} \mathrm{Cl}_{2} \\
\left(\mathrm{CH}_{3}\right)_{2} \mathrm{NH}^{++}+2-\mathrm{ClC}_{6} \mathrm{H}_{4} \mathrm{I} \\
\left(\mathrm{CH}_{3}\right)_{2} \mathrm{NH}^{\cdot+}+3-\mathrm{ClC}_{6} \mathrm{H}_{4} \mathrm{I} \\
\left(\mathrm{CH}_{3}\right)_{2} \mathrm{NH}^{+}+4-\mathrm{ClC}_{6} \mathrm{H}_{4} \mathrm{I}\end{array}$ & $\begin{array}{l}12.3 \\
13.6 \\
15.3[23(b)] \\
14.2 \\
14.2 \\
14.5 \\
17.2[23(b)] \\
17.2[23(b)] \\
17.2[23(b)]\end{array}$ & $\begin{array}{l}1.69 \\
1.70 \\
1.70[23(\mathrm{e})] \\
2.54 \\
1.72 \\
0.0 \\
1.93[23(\mathrm{c})] \\
1.39[23(\mathrm{c})] \\
0.46[23(\mathrm{c})]\end{array}$ & $\begin{array}{l}2.07 \\
2.05 \\
2.06 \\
2.61 \\
2.10 \\
1.52 \\
2.22 \\
1.96 \\
1.66\end{array}$ & \\
\hline
\end{tabular}

of a reaction $1^{\circ+}$ without (Fig. 1(a)) and with (Fig. 1(b)) collisional deactivation. However, even with collisional cooling of the halobenzene radical cations the formation of protonated methylamine, $m / z 32$, is observed with a branching ratio $k_{\text {ce }} / k_{\text {subst }}$ between $0.19\left(2^{+}\right)$and $0.32\left(3^{+}\right)$. Most of the $m / z$ 32 ions arise from an initial charge transfer from the aromatic radical cation to methylamine, but some may be formed by a proton transfer from the $N$-methyl-anilinium ion, the final substitution product, to methylamine. This proton transfer is endothermic (proton affinity PA(methylamine) $=$ $896 \mathrm{~kJ} \mathrm{~mol}^{-1}[15], \operatorname{PA}(N$-methylaniline $)=912.5 \mathrm{~kJ} \mathrm{~mol}^{-1}$ [15]), but occurs 


\section{TABLE 2}

Rate constants and efficiencies for the reactions of the radical cations of 1-9 with $\mathrm{CH}_{3} \mathrm{NH}_{2}$

\begin{tabular}{llllll}
\hline $\begin{array}{l}\text { Radical } \\
\text { ion }\end{array}$ & $\begin{array}{l}k_{\text {total }} \\
\left(10^{-10} \mathrm{~cm}^{3} \text { molecule }^{-1} \mathrm{~s}^{-1}\right)\end{array}$ & $\begin{array}{l}\text { eff } \\
(\%)\end{array}$ & $\begin{array}{l}k_{\text {subst }} \\
\left(10^{-10} \mathrm{~cm}^{3} \text { molecue }^{-1} \mathrm{~s}^{-1}\right)\end{array}$ & $\begin{array}{l}\text { eff }_{\text {subst }} \\
(\%)\end{array}$ & $k_{\mathrm{I}} / k_{\mathrm{Cl}}$ \\
\hline $\mathbf{1}^{++}$ & 11.0 & 67 & 8.7 & 53 & \\
$\mathbf{2}^{++}$ & 11.0 & 69 & 9.2 & 58 & \\
$\mathbf{3}^{++}$ & 7.6 & 49 & 5.7 & 37 & \\
$\mathbf{4}^{++}$ & 11.0 & 69 & 8.6 & 54 & \\
$\mathbf{5}^{++}$ & 8.6 & 54 & 5.5 & 34 & \\
$\mathbf{6}^{++}$ & 7.1 & 44 & 5.4 & 34 & \\
$\mathbf{7}^{++}$ & & & 7.3 & 47 & $1.4 \pm 0.2$ \\
$\mathbf{8}^{++}$ & & & 6.3 & 41 & $1.4 \pm 0.2$ \\
$\mathbf{9}^{++}$ & & & 4.4 & 28 & $1.8 \pm 0.3$ \\
\hline
\end{tabular}

because of some excess internal energy of the $N$-methylanilinium ions from the reaction enthalpy. However, the intensity ratio of the product ions of reactions (1) and (2), $m / z 108$ and $m / z 32$, of $1^{\circ+}-3^{\circ+}$ remains constant during the first periods of the reaction, and the branching ratio for substitution and charge exchange was determined therefrom.

Substitution of one halogen atom is also observed in the reactions of the radical cations of the $o$-, $m$ - and $p$-dichlorobenzenes 4-6 (Scheme 2) and of the $o-, m$ - and $p$-chloroiodobenzenes 7-9 (Scheme 2), respectively, with methylamine. The bimolecular rate constants, $k_{\text {exp }}$, are presented in Table 2 . The IEs of the dichlorobenzenes $(4,9.08 \mathrm{eV}[15] ; 5,9.11 \mathrm{eV}[15] ; \mathbf{6}, 8.89 \mathrm{eV}$ [15]) are again close to the IE of methylamine, and some charge exchange from the aromatic cations to methylamine accompanies the substitution in spite of the collisional "cooling" of the reacting ions. In contrast to the reaction of the chlorobenzene radical cation, a proton transfer from the substitution product of the dichlorobenzene radical cation, the corresponding $N$-methyl-chloroanilinium ion, to methylamine is definitely observed. Only the PAs of $m$ - and $p$-chloroaniline are known $\left(867 \mathrm{~kJ} \mathrm{~mol}^{-1}[15]\right.$ and $873 \mathrm{~kJ} \mathrm{~mol}^{-1}$ [15] respectively), and assuming a similar shift of the PA by the $N$-methyl group as in the case of aniline (PA $\left.=876.5 \mathrm{~kJ} \mathrm{~mol}^{-1}[15]\right)$ and $N$-methylaniline $\left(\mathrm{PA}=912.5 \mathrm{~kJ} \mathrm{~mol}^{-1}\right.$ [15]) the PA of the $N$-methyl-chloroanilines should be $905 \pm 10 \mathrm{~kJ} \mathrm{~mol}^{-1}$, only slightly larger than the PA(methylamine) of $896 \mathrm{~kJ} \mathrm{~mol}^{-1}$. As a consequence of this more or less thermoneutral proton transfer from the substitution product to methylamine the branching ratio $k_{\mathrm{ce}} / k_{\text {subst }}$ for $4^{{ }^{+}-6^{+}}$has to be determined by the less accurate method of initial slopes. The amount of charge transfer in these cases is similar to that for the chlorobenzene radical cation $\mathbf{1}^{+}$, however.

Negligible charge exchange to methylamine is observed for the reactions of 
the radical cations of the isomeric chloroiodobenzenes 7-9 if the reacting ions are properly deactivated by collisions with argon. The IEs of the chloroiodobenzenes are not known, but are obviously below the IE(iodobenzene) of $8.69 \mathrm{eV}$ [15]. Both the $\mathrm{Cl}$ and the I substituent, respectively, is lost during the reaction, giving rise to $N$-methyl-iodoanilinium and $N$-methyl-chloroanilinium ions respectively. Again a definite proton transfer from these substitution products to methylamine is observed. The PAs of the $N$-methyl-chloroanilines and $N$-methyl-iodoanilines are expected to be different, resulting in different rates of proton transfer from the anilinium ions to methylamine. As a consequence, the relative intensities of the $N$-methyl-chloroanilinium and $N$-methyl-iodoanilinium ions are influenced differently during the course of the reaction, and the branching ratio $k_{\mathrm{I}} / k_{\mathrm{Cl}}$ in the reactions of $7^{++}-9^{\cdot+}$ had to be determined by the method of initial slopes.

\section{Reactions of methylamine radical cations with monohalobenzenes and dihalobenzenes}

Substitution and/or charge exchange (reactions (3) and (4), respectively) are also observed if $\mathrm{CH}_{3} \mathrm{NH}_{2}^{+}$generated in the external ion source reacts with neutral 1-9 in the ICR cell:

$$
\begin{aligned}
\mathrm{CH}_{3} \mathrm{NH}_{2}^{++}+\mathrm{C}_{6} \mathrm{H}_{5} \mathrm{X} & \rightarrow \mathrm{C}_{6} \mathrm{H}_{5} \mathrm{NH}_{2} \mathrm{CH}_{3}^{+}+\mathrm{X}^{\cdot} \\
& \rightarrow \mathrm{CH}_{3} \mathrm{NH}_{2}+\mathrm{C}_{6} \mathrm{H}_{5} \mathrm{X}^{-+}
\end{aligned}
$$

For iodobenzene 3 and the chloroiodobenzenes 7-9 only charge exchange occurs under all experimental conditions. In all these cases charge exchange with $\mathrm{CH}_{3} \mathrm{NH}_{2}^{+}$is exothermic by at least $0.28 \mathrm{eV}$, and the substitution reaction can obviously not compete with exothermic charge exchange.

On the reactions of $\mathrm{CH}_{3} \mathrm{NH}_{2}^{+}$with chlorobenzene 1, bromobenzene 2, and the isomeric dichlorobenzenes 4-6 the substitution reaction usually dominates for ions carefully deactivated by collisions with argon. The bimolecular rate constants $k_{\text {total }}$ and $k_{\text {subst }}$ for the disappearance of $\mathrm{CH}_{3} \mathrm{NH}_{2}^{+}$and for the formation of the $N$-methylanilinium ions and $N$-methyl-chloroanilinium ions, respectively, are shown in Table 3 together with the corresponding reaction efficiencies eff total $=k_{\text {total }} / k_{\text {cap }}$ and eff $f_{\text {subst }}=k_{\text {subst }} / k_{\text {cap }}$.

Subsequent to the charge transfer, only a few further reactions (less than $5 \%$ of total product ions) of the aromatic radical cations with the neutral halobenzenes are observed, so that the branching ratio between charge exchange and substitution can be determined reliably by the constant intensity ratio of the products of reactions (3) and (4). The efficiency of the charge transfer is expected to increase with decreasing IE of the halobenzene, in line with its small intensity in the case of 5 (IE(1,3-dichlorobenzene) $=9.11 \mathrm{eV}$ [15]) and the dominance of this process in the case of the halobenzenes 
TABLE 3

Rate constants and efficiencies for the reactions of 1-9 with the radical cations $\left[\mathrm{CH}_{3} \mathrm{NH}_{2}\right]^{-+}$

\begin{tabular}{llllc}
\hline Halobenzene & $\begin{array}{l}k_{\text {total }} \\
\left(10^{-10} \mathrm{~cm}^{3} \text { molecule }\right.\end{array}$ & $\begin{array}{l}\left.\mathrm{cff}_{\text {total }} \mathrm{s}^{-1}\right) \\
(\%)\end{array}$ & $\begin{array}{l}k_{\text {subst }} \\
\left(10^{-10} \mathrm{~cm}^{3} \text { molecule }^{-1} \mathrm{~s}^{-1}\right)\end{array}$ & $\begin{array}{l}\text { eff } \\
(\%)\end{array}$ \\
\hline $\mathbf{1}$ & 15 & 63 & 13 & 55 \\
$\mathbf{3}$ & 18 & 76 & 15 & 63 \\
$\mathbf{4}$ & Only charge transfer & & & 50 \\
$\mathbf{5}$ & 17 & 56 & 15 & 54 \\
$\mathbf{6}$ & 14 & 58 & 13 & 57 \\
$\mathbf{7}$ & 16 & 91 & 10 & \\
$\mathbf{8}$ & Only charge transfer & & & \\
\hline
\end{tabular}

containing an iodo substituent (IE(iodobenzene) $=8.69 \mathrm{eV}[15])$. However, there are obviously other structural features which influence the charge transfer from $\mathrm{CH}_{3} \mathrm{NH}_{2}^{+}$to the halobenzenes. Thus, chlorobenzene and 1,2dichlorobenzene have nearly identical IEs $(9.06 \mathrm{eV}$ [15] and $9.08 \mathrm{eV}$, respectively) and similar efficiencies for a charge transfer, eff $\mathrm{ce}_{\mathrm{ce}}(8 \%$ and $6 \%$ respectively), while bromobenzene and 1,4-dicholorobenzene have also nearly identical IEs ( $8.98 \mathrm{eV}$ [15] and $8.99 \mathrm{eV}$ [15] respectively), but exhibit rather different eff ${ }_{c e}$ of $13 \%$ and $37 \%$ respectively. The origin of this effect has not yet been established.

\section{Reactions of dimethylamine radical cations with monohalobenzenes and dihalobenzenes}

The IE of dimethylamine of $8.23 \mathrm{eV}$ [15] is surely below that of all halobenzenes studied. Hence, a charge exchange of $\left(\mathrm{CH}_{3}\right)_{2} \mathrm{NH}^{+}$with the halobenzenes is only observed with an intensity of less than $15 \%$ during the first few milliseconds of the FT-ICR experiments owing to imperfect collisional cooling of the $\left(\mathrm{CH}_{3}\right)_{2} \mathrm{NH}^{+}$ions transferred. An exception is 1-chloro-3-iodobenzene (8), exhibiting charge exchange in competition with the substitution reaction. Other side-reactions or consecutive reactions are not observed, and the determination of the reaction kinetics of the substitution reaction is not disturbed by the small amount of charge transfer occurring during the initial stages of the reaction. The bimolecular rate constants $k_{\text {subst }}\left(=k_{\text {total }}\right)$ and the eff $f_{\text {subst }}$ are listed in Table 4. Generally, the reaction of $\left(\mathrm{CH}_{3}\right)_{2} \mathrm{NH}^{+}$with all halobenzenes studied is slow, and the very slow reaction with 1,3-dichlorobenzene (5) was monitored only to $30 \%$ conversion because of instrumental limitations. In the case of the isomcric chloroiodo derivatives 7-9 the substitution of the halogens competes with each other, and the branching ratio $k_{1} / k_{\mathrm{Cl}}$ varying 


\section{TABLE 4}

Rate constants and efficiencies for the reactions of 1-9 with the radical cations $\left[\left(\mathrm{CH}_{3}\right)_{2} \mathrm{NH}\right]^{\cdot+}$

\begin{tabular}{llll}
\hline Halobenzene & $\begin{array}{l}k_{\text {subst }} \\
\left(10^{-10} \mathrm{~cm}^{3} \text { molecule } \mathrm{s}^{-1}\right)\end{array}$ & $\begin{array}{l}\text { eff } \\
(\%)\end{array}$ & $k_{1} / k_{\mathrm{Cl}}$ \\
\hline 1 & 0.32 & 1.6 & \\
$\mathbf{2}$ & 0.94 & 4.6 & \\
$\mathbf{3}$ & 1.9 & 9.2 & \\
4 & 0.50 & 1.9 & \\
$\mathbf{5}$ & 0.024 & 0.11 & $1.4 \pm 0.1$ \\
6 & 0.25 & 1.6 & $2.5 \pm 0.3$ \\
7 & 3.0 & 14 & $2.6 \pm 0.2$ \\
8 & 0.32 & 1.5 & \\
9 & 1.1 & 6.6 & \\
\hline
\end{tabular}

between 1.4 and 2.6 was obtained directly from the intensity ratio of the corresponding product ions.

\section{DISCUSSION}

The previous investigations of the reactions of the radical cations of chloroethenes [9] and monohalobenzenes and dihalobenzenes [10], respectively, with $\mathrm{NH}_{3}$ have clearly established the addition/elimination mechanism depicted in Scheme 1. This is certainly also the mechanism of the radical cation substitution reactions between methylamine and the halogenated benzenes studied here. In this mechanism the first reaction step after the formation of a long-lived collision complex corresponds either to an addition of the nucleophile $\mathrm{NH}_{3}$ and $\mathrm{CH}_{3} \mathrm{NH}_{2}$ respectively, to the aromatic radical cation or to the addition of a radical cation $\mathrm{CH}_{3} \mathrm{NH}_{2}^{+}$and $\left(\mathrm{CH}_{3}\right)_{2} \mathrm{NH}^{+}$, respectively, to the neutral halogenated benzene. In both reaction pathways the same distonic ion is formed as an intermediate, consisting of a (possibly methylated) ammonium group attached to a cyclohexadienyl radical. This distonic ion eventually dissociates by loss of a halogen atom. Very likely this last reaction step has no extra energy barrier besides the dissociation energy of the C-halogen bond cleaved and will be controlled by its thermochemistry. To the contrary, the addition step should exhibit an appreciable activation barrier because of the considerable valence-electron rearrangements involved, and the curve crossing model of Shaik and Pross [4] predicts principally a larger activation energy in the case of a nucleophilic addition to the aromatic radical cation. Thus the substitution reaction is represented schematically by the reaction energy profile of Fig. 2.

Naturally, the exothermicity of the addition step, starting from the long- 
(a)

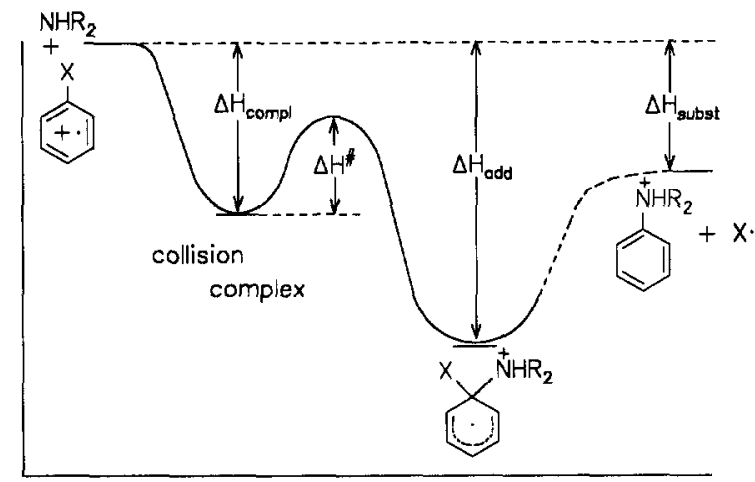

(b)

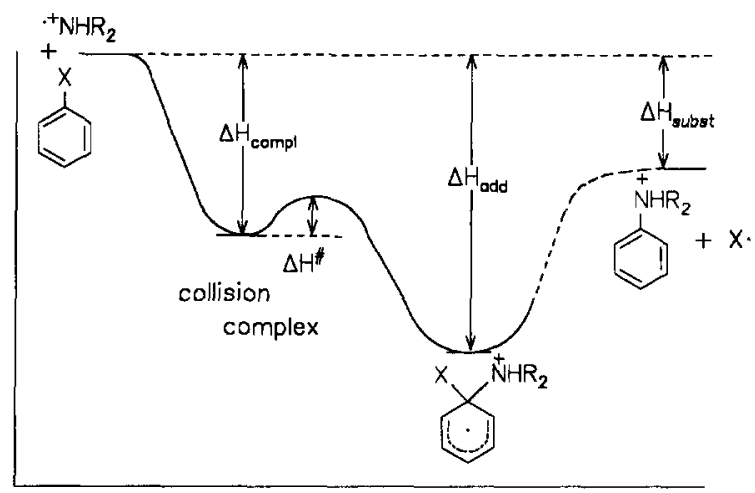

Fig. 2. Schematic reaction enthalpy profile for the reaction of (a) halobenzene radical cation with neutral $\mathrm{NHR}_{2}$, (b) neutral halobenzene with $\left[\mathrm{NHR}_{2}\right]^{+}\left(\mathrm{R}=\mathrm{H}, \mathrm{CH}_{3}\right): \Delta H_{\text {compl }}$, electrostatic binding enthalpy of the collision complex; $\Delta H_{\text {add }}$, reaction enthalpy of the addition step; $\Delta H_{\text {subst }}$, reaction enthalpy of the total substitution process; $\Delta H^{*}$, activation enthalpy of the addition step.

lived collision complex, has an influence also on the height of the activation barrier besides the activation energy arising from the avoided crossing of the energy curves of the Shaik-Pross model, representing the energy variation of the ground state and the relevant excited state of the reactants along the reaction coordinate. We have shown previously [10] that the addition of $\mathrm{NH}_{3}$ to the radical cations of halogenated benzenes depends on the type, the number and the orientation of the halogen substituents. However, the effect of the structure of the nucleophile is not known. The thermochemical data available for an evaluation of the thermochemistry of the reactions discussed herc are shown in Table 5. The heats of formation, $\Delta H_{\mathrm{f}}^{\circ}$, of methylamine and dimethylamine and of their radical cations as well as those of the monohalobenzenes and their radical cations are well known [15]. In the case of the dihalobenzenes, only the $\Delta H_{\mathrm{f}}^{\circ}$ values of the dichlorobenzenes and of the respective radical ions are available [15]. With respect to the reaction products 


\section{TABLE 5}

Heats of formation, $\Delta H_{f}\left(\mathrm{~kJ} \mathrm{~mol}^{-1}\right)$, of amines and of 1-6, their radical cations, and anilinium ions (experimental values from ref. 15; calculated values by AM1)

\begin{tabular}{|c|c|c|c|c|c|c|}
\hline \multirow[t]{2}{*}{ Compound $\mathbf{M}$} & \multicolumn{2}{|l|}{$\Delta H_{\mathrm{f}}(\mathrm{M})$} & \multicolumn{2}{|c|}{$\Delta H_{\mathrm{f}}\left(\mathbf{M}^{\cdot+}\right)$} & \multicolumn{2}{|c|}{$\Delta H_{\mathrm{f}}\left(\mathrm{MH}^{+}\right)$} \\
\hline & Exp. & AMl & Exp. & AM 1 & Exp. & $\Lambda \mathrm{M} 1$ \\
\hline $\begin{array}{l}\mathrm{NH}_{3} \\
\mathrm{CH}_{3} \mathrm{NH}_{2} \\
\left(\mathrm{CH}_{3}\right)_{2} \mathrm{NH}\end{array}$ & $\begin{array}{l}-46.0 \\
-23.0 \\
-18.4\end{array}$ & $\begin{array}{l}-30 \\
-29 \\
-21\end{array}$ & $\begin{array}{l}933.9 \\
841.0 \\
774.0\end{array}$ & $\begin{array}{l}876 \\
820 \\
784\end{array}$ & & \\
\hline $\begin{array}{l}\mathrm{C}_{6} \mathrm{H}_{5} \mathrm{Cl}(1) \\
\mathrm{C}_{6} \mathrm{H}_{5} \mathrm{Br}(2) \\
\mathrm{C}_{6} \mathrm{H}_{5} \mathrm{I}(3)\end{array}$ & $\begin{array}{r}54.4 \\
104.2 \\
164.8\end{array}$ & 62 & $\begin{array}{r}928.8 \\
970.7 \\
1004.2\end{array}$ & 942 & & \\
\hline $\begin{array}{l}1,2-\mathrm{C}_{6} \mathrm{H}_{4} \mathrm{Cl}_{2}(4) \\
1,3-\mathrm{C}_{6} \mathrm{H}_{4} \mathrm{Cl}_{2}(5) \\
1,4-\mathrm{C}_{6} \mathrm{H}_{4} \mathrm{Cl}_{2}(6)\end{array}$ & $\begin{array}{l}33.0 \\
28.0 \\
24.7\end{array}$ & & $\begin{array}{l}902.2 \\
907.0 \\
882.4\end{array}$ & & & \\
\hline $\begin{array}{l}\mathrm{C}_{6} \mathrm{H}_{5} \mathrm{NH}_{2} \\
\mathrm{C}_{6} \mathrm{H}_{5} \mathrm{NHCH}_{3} \\
\mathrm{C}_{6} \mathrm{H}_{5} \mathrm{~N}\left(\mathrm{CH}_{3}\right)_{2}\end{array}$ & & & & & $\begin{array}{l}740.6 \\
703.0 \\
694.5\end{array}$ & $\begin{array}{l}739 \\
746 \\
765\end{array}$ \\
\hline
\end{tabular}

the $\Delta H_{\mathrm{f}}^{\circ}$ values of the anilinium ions, $N$-methylanilinium ions and $N, N$-dimethylanilinium ions are tabulated [15], but in the case of halogenated anilines only $\Delta H_{\mathrm{f}}^{\circ}$ values of 3- and 4-chloroanilinium ions are known. These latter values can, however, be used to estimate the $\Delta H_{\mathrm{f}}^{\circ}$ of the corresponding $N$-methylchloroanilinium and $N, N$-dimethylchloroanilinium ions, assuming identical effects of the $N$-methyl groups on the PA as in the case of aniline, $N$-methylaniline and $N, N$-dimethylaniline.

No experimental $\Delta H_{\mathrm{f}}^{\circ}$ values are accessible for the intermediate distonic ions generated by the addition step. Hence, the $\Delta H_{\mathrm{r}}^{\circ}$ values of these intermediates were calculated by the semiempirical SCF MO method AM1 [24]. This method reproduces the $\Delta H_{\mathrm{f}}^{\circ}$ of neutral and charged species usually quite well [24] and has been used to calculate PAs of a variety of bases [25]. To test the AMl method for the present system we have calculated $\Delta H_{f}^{\circ}$ of the neutral and ionic species of the reactions of chlorobenzene 1 , in addition to $\Delta H_{\mathrm{f}}^{\circ}$ of the reaction intermediates. The values obtained are also listed in Table 5. The results are not very encouraging both for the amine radical cations and the anilinium ions because of a large and systematic deviation from the experimental values of $\Delta H_{\mathrm{f}}^{\circ}$ owing to the successive introduction of $N$-methyl groups. The inability of AM1 to reproduce the correct PAs of tertiary amines has been noted before [25(a)]. In the present case, AM1 reproduces $\Delta H_{\mathrm{f}}^{\circ}$ (anilinium ion) correctly [25(a)], while the $\Delta H_{\mathrm{f}}^{\circ}$ values of the $N$-methyl- 
anilinium and $N, N$-dimethylanilinium ions are too high by 40 and $71 \mathrm{~kJ} \mathrm{~mol}^{-1}$ respectively. Similarly, the radical cation of $\mathrm{NH}_{3}$ is calculated to be $58 \mathrm{~kJ} \mathrm{~mol}^{-1}$ too unstable while at the other extreme that of dimethylamine is too stable by $10 \mathrm{~kJ} \mathrm{~mol}^{-1}$. Thus AM1 can be used with confidence only to calculate the PA of primary amines and the $\Delta H_{\mathrm{f}}^{\circ}$ of the corresponding ammonium ions. Therefore the calculated $\Delta H_{\mathrm{f}}^{\circ}$ value of $821 \mathrm{~kJ} \mathrm{~mol}^{-1}$ of the intermediate distonic ion generated by the addition of $\mathrm{NH}_{3}$ to the radical cation of chlorobenzene was corrected empirically for the mean effect of one and two methyl groups to estimate $\Delta H_{\mathrm{f}}^{\circ}$ of the $N$-methyl and $N, N$-dimethyl derivatives. For simple aliphatic primary ammonium ions, $\Delta H_{f}^{\circ}$ decreases by the introduction of one and two $N$-methyl groups by approximately $22 \mathrm{~kJ} \mathrm{~mol}^{-1}$ and $45 \mathrm{~kJ} \mathrm{~mol}^{-1}$ respectively [15]. Using this relationship, $\Delta H_{\mathrm{f}}^{\circ}=799 \mathrm{~kJ} \mathrm{~mol}^{-1}$ and $\Delta H_{\mathrm{f}}^{\circ}=776 \mathrm{~kJ} \mathrm{~mol}^{-1}$ are obtained for the $N$ methylated and $N, N$-dimethylated distonic ion respectively. Finally, the reaction energies for the addition step and the total substitution reaction were calculated as shown in Table 6 from the experimental $\Delta H_{\mathrm{f}}^{\circ}$ values available and the estimated $\Delta H_{\mathrm{f}}^{\circ}$ values of the distonic ions.

The substitution of the monohalobenzene radical cations $1^{\cdot+}-3^{\cdot+}$ by methylamine is exothermic by $-81.5 \mathrm{~kJ} \mathrm{~mol}^{-1}$ for the chloro substituent, and the exothermicity increases for the bromo and iodo substituent to -132.0 and $-171.5 \mathrm{~kJ} \mathrm{~mol}^{-1}$ respectively. Clearly, the exchange of the nucleophile $\mathrm{NH}_{3}$ by $\mathrm{CH}_{3} \mathrm{NH}_{2}$ makes the substitution more exothermic by about $60 \mathrm{~kJ} \mathrm{~mol}^{-1}$, owing mainly to the increased stability of the $N$-methylanilinium product ions. A further increase in the exothermicity is calculated for the substitution of the monohalobenzene radical cations by dimethylamine, but in this case only charge exchange is observed experimentally. As for the reaction of the chlorobenzene radical cations with $\mathrm{NH}_{3}$, the addition of $\mathrm{CH}_{3} \mathrm{NH}_{2}$ to the aromatic radical cation is calculated to be more exothermic than the total substitution reaction. However, the effect of one $N$-methyl group on the stability of the intermediate distonic ion is less $\left(45 \mathrm{~kJ} \mathrm{~mol}^{-1}\right)$ than on the product ion. In spite of its exothermicity, the first addition step is rate determining in the case of $\mathrm{NH}_{3}$ because of an "intrinsic" barrier arising mainly from the IE difference of the reactants [10] according to the curve crossing model. The IE of $\mathrm{CH}_{3} \mathrm{NH}_{2}$ is $1.19 \mathrm{eV}$ below the IE of $\mathrm{NH}_{3}$. Thus, for $\mathrm{CH}_{3} \mathrm{NH}_{2}$ the curve crossing model predicts a reduced intrinsic barrier. According to the Bell-Evans-Polanyi principle [26], the increased exothermicity of the addition step results in a further reduction of its activation energy. Hence, the efficiency of the subsitution reaction of the halobenzene radical cations with $\mathrm{CH}_{3} \mathrm{NH}_{2}$ is expected to be quite large by these combined effects. This is borne out by the experiment, resulting in eff subst $_{\text {of }} 53 \%, 58 \%$ and $37 \%$ for $1^{++}, \mathbf{2}^{++}$and $3^{+}$, respectively, compared to eff $f_{\text {subst }}<15 \%$ [10] for the same reactions using $\mathrm{NH}_{3}$ as a nucleophile. The eff subst of the iodobenzene radical cation $3^{+}$ 


\section{TABLE 6}

Reaction enthalpy, $\Delta H_{\text {subst }}\left(\mathrm{kJ} \mathrm{mol}^{-1}\right)$, for the reactions of 1-3, 5, and 6, and of their radical cations with $\left[\mathrm{R}_{2} \mathrm{NH}\right]^{+}$and $\mathrm{R}_{2} \mathrm{NH}$ respectively ( $\Delta H_{\text {add }}$ enthalpy of the addition step)

\begin{tabular}{|c|c|c|c|c|}
\hline $\mathbf{R}$ & $\mathbf{R}$ & $X$ & $\Delta H_{\text {add }}$ & $\Delta H_{\text {subst }}$ \\
\hline \multicolumn{5}{|c|}{$\mathrm{C}_{6} \mathrm{H}_{5} \mathrm{X}^{\cdot+}+\mathrm{HNR}_{2} \rightarrow \mathrm{C}_{6} \mathrm{H}_{5}(\mathrm{X}) \mathrm{N}^{+} \mathrm{HR}_{2} \rightarrow \mathrm{C}_{6} \mathrm{H}_{5} \mathrm{~N}^{+} \mathrm{HR}_{2}+\mathrm{X}$} \\
\hline $\mathrm{H}$ & $\mathrm{H}$ & $\mathrm{Cl}(\mathbf{1})$ & -61.8 & -20.9 \\
\hline $\mathbf{H}$ & $\mathrm{CH}_{3}$ & $\mathrm{Cl}(\mathbf{1})$ & -106.8 & -81.5 \\
\hline $\mathrm{CH}_{3}$ & $\mathrm{CH}_{3}$ & $\mathrm{Cl}(\mathbf{1})$ & -135.4 & -94.6 \\
\hline $\mathrm{H}$ & $\mathrm{H}$ & $\operatorname{Br}(2)$ & & -72.4 \\
\hline $\mathrm{H}$ & $\mathrm{CH}_{3}$ & $\operatorname{Br}(2)$ & & -132.0 \\
\hline $\mathrm{CH}_{3}$ & $\mathrm{CH}_{3}$ & $\mathrm{Br}(2)$ & & -146.1 \\
\hline $\mathbf{H}$ & $\mathbf{H}$ & I (3) & & -110.9 \\
\hline $\mathrm{H}$ & $\mathrm{CH}_{3}$ & I (3) & & -171.5 \\
\hline $\mathrm{CH}_{3}$ & $\mathrm{CH}_{3}$ & I (3) & & -184.6 \\
\hline \multicolumn{5}{|c|}{$1,3-\mathrm{C}_{6} \mathrm{H}_{4} \mathrm{Cl}_{2}^{-+}+\mathrm{HNR}_{2} \rightarrow 3-\mathrm{Cl}-\mathrm{C}_{6} \mathrm{H}_{4} \mathrm{~N}^{+} \mathrm{HR}_{2}+\mathrm{Cl} \cdot$} \\
\hline $\mathrm{H}$ & H & $\mathrm{Cl}(\mathbf{5})$ & & -20.1 \\
\hline $\mathrm{H}$ & $\mathrm{CH}_{3}$ & $\mathrm{Cl}(\mathbf{5})$ & & -80.7 \\
\hline $\mathbf{H}$ & $\mathrm{CH}_{3}$ & $\mathrm{Cl}(\mathbf{5})$ & & -94.3 \\
\hline \multicolumn{5}{|c|}{$1,4-\mathrm{C}_{6} \mathrm{H}_{4} \mathrm{Cl}_{2}^{\cdot+}+\mathrm{HNR}_{2} \rightarrow 4-\mathrm{Cl}-\mathrm{C}_{6} \mathrm{H}_{4} \mathrm{~N}^{+} \mathrm{HR}_{2}+\mathrm{Cl} \cdot$} \\
\hline $\mathbf{H}$ & $\mathbf{H}$ & $\mathrm{Cl}(6)$ & & -3.4 \\
\hline $\mathbf{H}$ & $\mathrm{CH}_{3}$ & $\mathrm{Cl}(6)$ & & -63.7 \\
\hline $\mathrm{H}$ & $\mathrm{CH}_{3}$ & $\mathrm{Cl}(6)$ & & -77.3 \\
\hline \multicolumn{5}{|c|}{$\mathrm{C}_{6} \mathrm{H}_{5} \mathrm{X}+\mathrm{HNR}_{2}^{\cdot+} \rightarrow \mathrm{C}_{6} \mathrm{H}_{5}(\mathrm{X}) \mathrm{N}^{+} \mathrm{HR}_{2} \rightarrow \mathrm{C}_{6} \mathrm{H}_{5} \mathrm{~N}^{+} \mathrm{HR}_{2}+\mathrm{X} \cdot$} \\
\hline $\mathrm{H}$ & $\mathrm{H}$ & $\mathrm{Cl}(1)$ & -167.3 & -126.4 \\
\hline $\mathbf{H}$ & $\mathrm{CH}_{3}$ & $\mathrm{Cl}(\mathbf{1})$ & -96.4 & -71.1 \\
\hline $\mathrm{CH}_{3}$ & $\mathrm{CH}_{3}$ & $\mathrm{Cl}(\mathbf{1})$ & -53.4 & -12.6 \\
\hline $\mathbf{H}$ & $\mathbf{H}$ & $\mathrm{Br}(2)$ & & -185.8 \\
\hline $\mathrm{H}$ & $\mathrm{CH}_{3}$ & $\mathrm{Br}(2)$ & & -130.5 \\
\hline $\mathrm{CH}_{3}$ & $\mathrm{CH}_{3}$ & $\mathrm{Br}(2)$ & & -72.0 \\
\hline $\mathrm{H}$ & $\mathrm{H}$ & I (3) & & -251.4 \\
\hline $\mathrm{H}$ & $\mathrm{CH}_{3}$ & I (3) & & -196.1 \\
\hline $\mathrm{CH}_{3}$ & $\mathrm{CH}_{3}$ & I (3) & & -125.0 \\
\hline \multicolumn{5}{|c|}{$1,3-\mathrm{C}_{6} \mathrm{H}_{4} \mathrm{Cl}_{2}+\mathrm{HNR}_{2}^{++} \rightarrow 3-\mathrm{Cl}-\mathrm{C}_{6} \mathrm{H}_{4} \mathrm{~N}^{+} \mathrm{HR}_{2}+\mathrm{Cl} \cdot$} \\
\hline $\mathrm{H}$ & $\mathrm{H}$ & $\mathrm{Cl}(5)$ & & -121.0 \\
\hline $\mathbf{H}$ & $\mathrm{CH}_{3}$ & $\mathrm{Cl}(\mathbf{5})$ & & -65.7 \\
\hline $\mathrm{H}$ & $\mathrm{CH}_{3}$ & $\mathrm{Cl}(\mathbf{5})$ & & -7.7 \\
\hline \multicolumn{5}{|c|}{$1,4-\mathrm{C}_{6} \mathrm{H}_{4} \mathrm{Cl}_{2}+\mathrm{HNR}_{2}^{++} \rightarrow 4-\mathrm{Cl}-\mathrm{C}_{6} \mathrm{H}_{4} \mathrm{~N}^{+} \mathrm{HR}_{2}+\mathrm{Cl}$} \\
\hline $\mathbf{H}$ & $\mathbf{H}$ & $\mathrm{Cl}(\mathbf{6})$ & & -126.0 \\
\hline $\mathrm{H}$ & $\mathrm{CH}_{3}$ & $\mathrm{Cl}(\mathbf{6})$ & & -70.4 \\
\hline $\mathrm{H}$ & $\mathrm{CH}_{3}$ & $\mathrm{Cl}(6)$ & . & -12.4 \\
\hline
\end{tabular}


is somewhat reduced, probably indicating a larger activation barrier owing to a larger initial energy gap $\Delta E_{\mathrm{G}}$ from the low IE of iodobenzene. Indeed, the

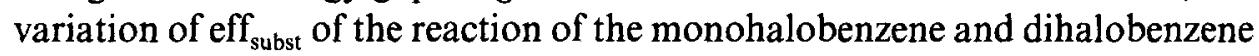
radical cations with $\mathrm{CH}_{3} \mathrm{NH}_{2}$ follows closely the effects observed for the reactions with $\mathrm{NH}_{3}$ [10(a)], although all of the former reactions are much faster. In particular, the eff $f_{\text {subst }}$ of 1,2-chloroiodobenzene 7 exceeds somewhat the value for iodobenzene 3 , while the eff subst $_{\text {of }}$ of the 1,3-isomer 8 is about the same and that of the 1,4-isomer 9 is distinctly smaller than that of $\mathbf{3}$. This reduced reactivity of the para isomer is an additional example of the effect of a different electrostatic interaction between the reactants in the ground state and the relevant excited state on the initial energy gap $\Delta E_{\mathrm{G}}$ and the activation energy [10(a)]. Thus, the present results confirm the mechanism suggested for the reactions of aromatic radical cations with nucleophiles and show that the curve crossing model predicts correctly the structural effects for these reactions.

Contrasting the nucleophilic substitution of halobenzene radical cations by neutral $\mathrm{NH}_{3}$ or $\mathrm{CH}_{3} \mathrm{NH}_{2}$, the reaction of an amine radical cation (an electron deficient species) with a neutral halobenzene represents an electrophilic substitution. Both reactions start with an addition step, and the treatment of this reaction by the curve crossing model is schematically depicted in Fig. 3. To a first approximation, the relevant states of the reactants which have to be considered for the initial energy gap are in the former case (Fig. 3(a)) the ground state and a double-excited state consisting of a triplet benzene and the ionized amine in the latter case the ground state and only a single-excited state containing the triplet state of the neutral halobenzene and the amine radical cation (Fig. 3(b)). In the latter case, the coupling of the single electron of the radical cation and of one of the single electrons of the halobenzene triplet gives rise to the new bond in the product. The energy difference between the triplet state and singlet state of the halobenzenes does not change much with the type and the number of the halogen substituents. Hence, the intrinsic barrier related to the initial energy gap is not expected to vary much for this electrophilic substitution of neutral halobenzenes. Furthermore, the reactant states responsible for the initial energy gap of this reaction have the identical charge distribution and similar electrostatic interaction between the reactants, differing only by the polarizabilities of the halobenzenes in their singlet and triplet states. Thus, the orientation effect observed for the reactions of dihalogenated benzene radical cations with a nucleophile, which has been attributed to the large differences of the electrostatic interaction of the reactants in their excited state and their ground state because of the different charge distribution of these states [10(a)], should not appear in the electrophilic reactions of the amine radical cation with neutral halobenzenes. 
(a) addition of $\mathrm{NHR}_{2}$ to the halobenzene radical cotion

reactant ground state reactant excited state

(b) addition of $\left[\mathrm{NHR}_{2}\right]^{+ \text {. }}$ to the neutral halobenzene

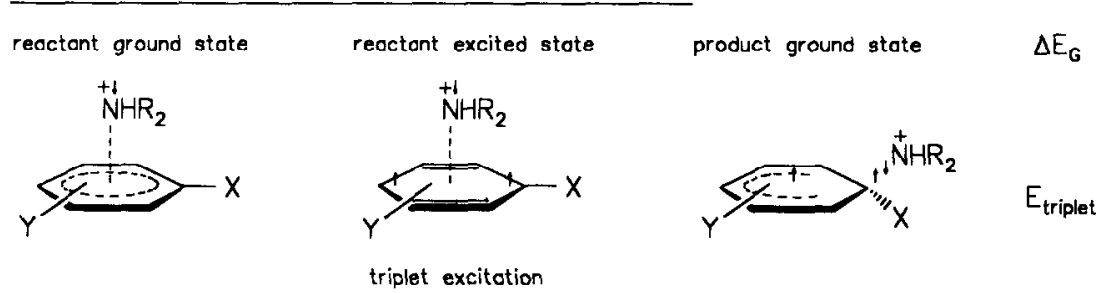

Fig. 3. Relevant valence bond states of the configuration mixing model for the formation of the intermediate distonic ion by (a) the addition of neutral $\mathrm{NHR}_{2}$ to halobenzene radical cation, (b) the addition of $\left[\mathrm{NHR}_{2}\right]^{+}$to neutral halobenzene.

The reactions of the radical cations $\mathrm{HNR}_{2}^{+}\left(\mathrm{R}=\mathrm{H}, \mathrm{CH}_{3}\right)$ with the halobenzenes 1-9 are exothermic (Table 6), the exothermicity decreasing from $\mathrm{NH}_{3}^{+}$to $\mathrm{HN}\left(\mathrm{CH}_{3}\right)_{2}^{\cdot+}$ and increasing from a substitution of $\mathrm{Cl}$ to that of $\mathrm{I}$. The estimation of the reaction enthalpy shows that also for this electrophilic substitution the first addition step is very exothermic. In combination with the reduced initial energy gap according to the curve crossing model this predicts that the activation energy for the addition step is small and probably not rate determining any more. The most exothermic substitution by $\mathrm{NH}_{3}{ }^{+}$is experimentally not accessible because of the fast charge exchange [13]. Similarly, only charge exchange is observed for the reaction of $\mathrm{CH}_{3} \mathrm{NH}_{2}^{+}$with the iodobenzenes 3 and 7-9. However, the substitution reaction of the remaining halobenzenes 1,2 and 4-6 by $\mathrm{CH}_{3} \mathrm{NH}_{2}^{+}$is always fast and exhibits no orientation effect in the case of the isomeric dichlorobenzenes 4-6, as predicted, but conceivably the large exothermicity of these reactions resulting in eff $f_{\text {subst }}>50 \%$ levels any structural effects. The reaction of $\left(\mathrm{CH}_{3}\right)_{2} \mathrm{NH}^{++}$ with the halobenzenes 1-9 is less exothermic, varying between about $10 \mathrm{~kJ} \mathrm{~mol}^{-1}$ and about $125 \mathrm{~kJ} \mathrm{~mol}^{-1}$ for the substitution of $\mathrm{Cl}$ and I respectively, and is not disturbed by a competing charge transfer. The substitution reactions of $\left(\mathrm{CH}_{3}\right)_{2} \mathrm{NH}^{+}$are always slow, however, even in the case of the very exothermic reaction with iodobenzene. The increase in the reaction energy of 
more than $100 \mathrm{~kJ} \mathrm{~mol}^{-1}$ between the reaction of 1 and 3 results only in an

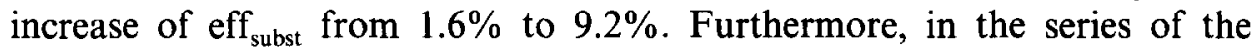
isomeric dichlorobenzenes 4-6 and chloroiodobenzenes 7-9 the reactivity of the meta isomer is reduced by nearly one order of magnitude.

The reason for these effects is not obvious. The addition step is always rather exothermic, comparable to the addition of the neutral amine to the aromatic radical cation, and predicted by the curve crossing model to exhibit only a small intrinsic activation barrier. Hence, the electrophilic addition of the amine radical cation to a neutral halobenzene should be at least as swift as the addition of the neutral amine to the halobenzene radical cation. The final dissociation step is identical for both types of substitution process and also is not expected to impose a large additional energy barrier on the reaction coordinate besides the dissociation energy of the carbon-halogen bond. Hence, any exothermic substitution of a neutral halobenzene by a radical cation should proceed at least with the efficiency of the process with the reversed charge distribution of the reactants, if only these two reaction steps are involved. Indeed, the study of the substitution reactions of the isomeric dichloroethenes with ionized amines [9] has already indicated that this is very likely an over-simplification of the mechanism, and that rearrangement steps of the initially generated distonic ion into an isomer with the correct configuration for the final dissociation step have to be considered.

It is not very likely that the addition step generates straightaway the ipso-substituted intermediate. In fact, a MNDO calculation of $\Delta H_{\mathrm{f}}^{\mathrm{O}}[10(\mathrm{a})]$ of the isomeric distonic ions, formed either by the addition of $\mathrm{NH}_{3}$ to the chlorobenzene radical cations or the addition of $\mathrm{NH}_{3}^{+}$to chlorobenzene, reveals that the ipso product required for the eventual loss of the $\mathrm{Cl}$ substituent is the least stable isomer. The most stable one arises from an addition at the para position (Scheme 3) and is more stable by $19 \mathrm{~kJ} \mathrm{~mol}^{-1}$. Assuming as before that the $N$-methyl groups enhance the PA of the amino group of the intermediate identically to the PA of aliphatic amines, this effect carries over to the distonic ions generated as intermediates from $\mathrm{CH}_{3} \mathrm{NH}_{2}$ or $\left(\mathrm{CH}_{3}\right)_{2} \mathrm{NH}$ and the respective radical cations. Thus, a priori one has to expect a preferred generation of para-substituted intermediates which are unreactive with respect to a direct dissociation, and which have to rearrange by migration of the amino group around the ring.

Rearrangements of $\beta$-distonic ions by a 1,2-shift of $\mathrm{NH}_{3}$ along a carbon skeleton are known [27], and theoretical calculations [28] have identified an activation barrier of $122 \mathrm{~kJ} \mathrm{~mol}^{-1}$ [28(b)] for this reaction. Thus, the additional rearrangement steps necessary to convert the para (or any other) adduct into the ipso isomer may become rate determining for the substitution process. As long as the preceding addition step exhibits the largest activation barrier along the reaction path, the intermediate distonic ion arises as a 

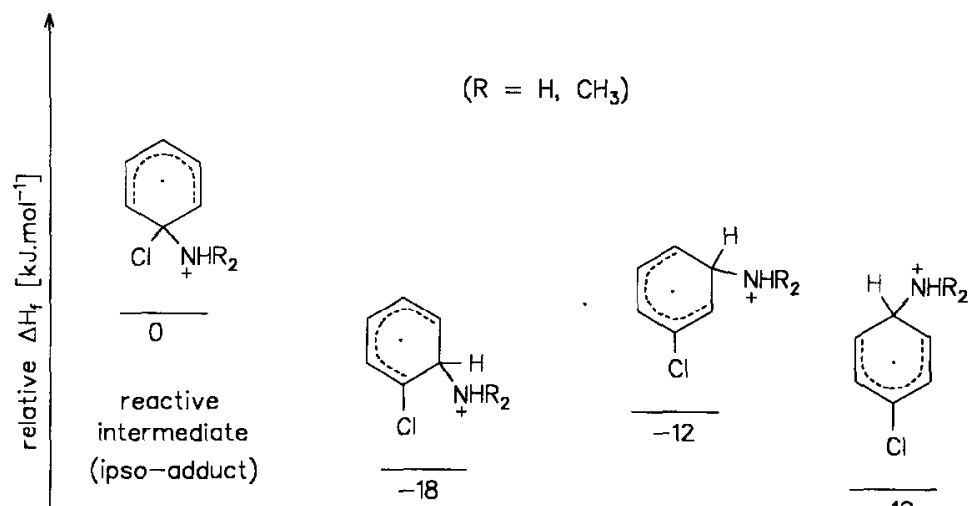

non-reoctive intermediates

$-19$

Scheme 3 .

chemically activated species with a large excess energy. If the activation energy of the rearrangement into the ipso isomer is not too large, the 1,2 shifts of the amino group are fast and not rate determining. This is obviously the case for the addition of $\mathrm{NH}_{3}$ to halobenzene radical cations [10]. A similar situation exists for the addition of $\mathrm{CH}_{3} \mathrm{NH}_{2}$ to halobenzene radical cations, even more so because of the increased exothermicity of the total process. In line with this assumption of a chemically excited intermediate is the low sensitivity of about 3 and 1.5 observed for the substitution of $\mathrm{I}$ vs. $\mathrm{Cl}$ of $7^{++}-9^{++}$with $\mathrm{NH}_{3}[10]$ and $\mathrm{CH}_{3} \mathrm{NH}_{2}$ respectively.

The substitution reaction of $\mathrm{CH}_{3} \mathrm{NH}_{2}^{+}$with the halobenzenes studied is rather exothermic. It has already been argued that this may level any structural effects during this reaction, in spite of a low activation barrier of the addition step. However, the substitution reaction of $\left(\mathrm{CH}_{3}\right)_{2} \mathrm{NH}^{+}$is much less exothermic, and in this case an effect of an activation energy barrier of the rearrangement of the initially generated distonic ion into the ipso isomer is likely to be observed. The result, that the substitution reaction of the iodobenzene 3 with $\left(\mathrm{CH}_{3}\right)_{2} \mathrm{NH}^{+}$is still slow, and that the isomeric chloroiodobenzenes 7-9 still exhibit a low selectivity for the loss of I vs. $\mathrm{Cl}$ of about two, hints again to the eventual dissociation of an excited species. We suggest that this chemical activation arises from a rate-determining rearrangement of the initially generated addition product. The especially low reactivity of the meta isomers 5 and $\mathbf{8}$ follows directly from this assumption. The relative $\Delta H_{\mathrm{f}}^{\circ}$ of the various distonic ions containing $\mathrm{NH}_{3}$ and the isomeric dichlorobenzenes 4-6 were calculated by MNDO [10(a)] and are depicted in Scheme 4. The "unreactive" species derived from the $o$ - and $p$-dichlorobenzenes are more stable by $12 \pm 1 \mathrm{~kJ} \mathrm{~mol}^{-1}$ than the "reactive" ipso isomers. The $m$-dichlorobenzene, however, gives rise to three isomeric addition products, more stable by 
$24 \pm 1 \mathrm{~kJ} \mathrm{~mol}^{-1}$ than the ipso adduct. So even if the intermediate distonic ion has enough excess energy to pass over the activation barriers of the rearrangement steps, the probability of the adduct ion formed from the metasubstituted dihalobenzenes to adopt the ipso configuration necessary for the final dissociation is comparatively small.

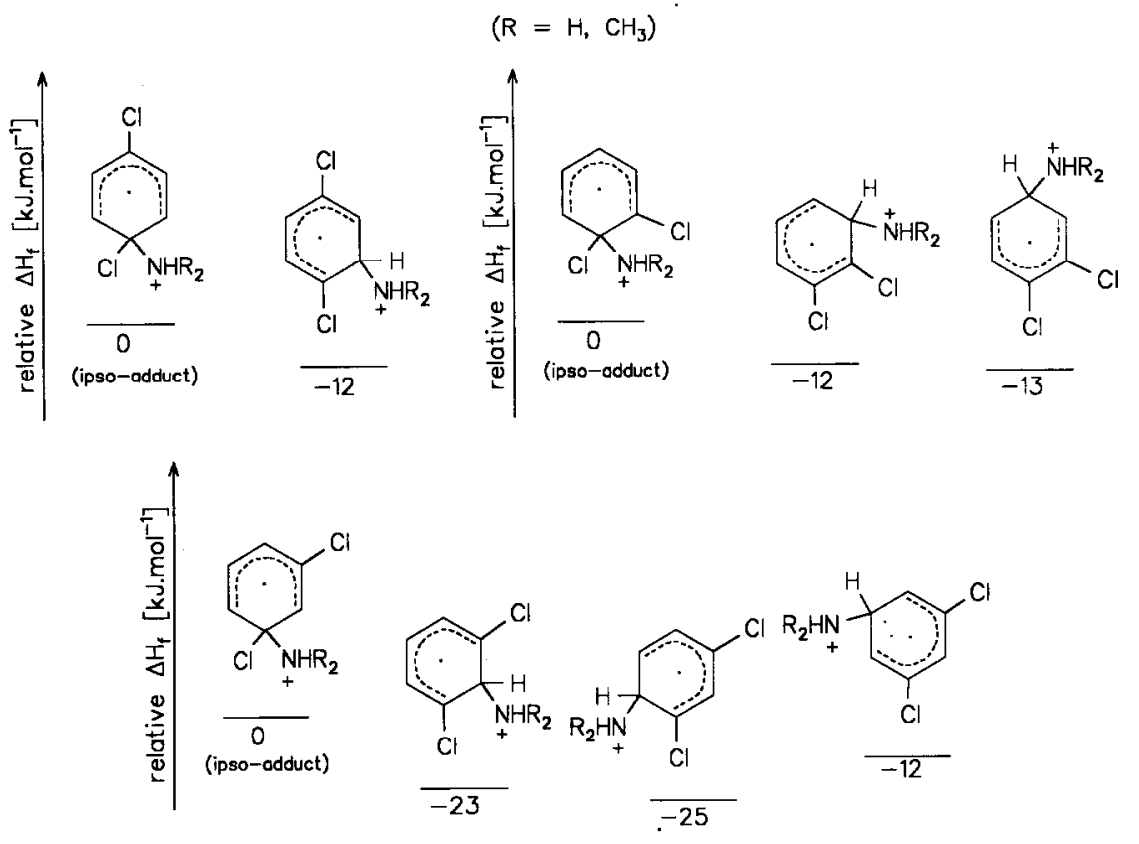

Scheme 4.

In the absence of any reliable theoretical calculations of the reaction pathway of the substitution reaction it is difficult to estimate the effect of the $N$-methyl groups in the series $\mathrm{NH}_{3}, \mathrm{CH}_{3} \mathrm{NH}_{2},\left(\mathrm{CH}_{3}\right)_{2} \mathrm{NH}$, in particular for the rearrangement steps. Both in the substitution reactions of dichloroethenes [9] and in the reactions studied here the influence of the rearrangements of the intermediate addition product is felt most in the case of the addition of $\left(\mathrm{CH}_{3}\right)_{2} \mathrm{NH}^{\cdot+}$. This may be an effect of the reduced exothermicity alone, but apparently the activation barrier of the rearrangement by a 1,2-shift of the amino group increases also with methylation.

For an application of the curve crossing model to the rearrangement of a $\beta$-distonic ammonium ion by a 1,2-shift of an $\mathrm{NR}_{3}$ group, three states with a different electronic configuration have to be considered to evaluate the initial energy gap $\Delta E_{\mathrm{G}}$ and the variation of energy of the system along the reaction coordinate (Fig. 4). Three valence electrons take part in the rearrangement, two of them forming the bonding electron pair of the $\mathrm{C}_{\alpha}-\mathrm{N}$ bond, while the third one is the radical electron at $C_{\beta}$ in the ground state of the initial distonic 


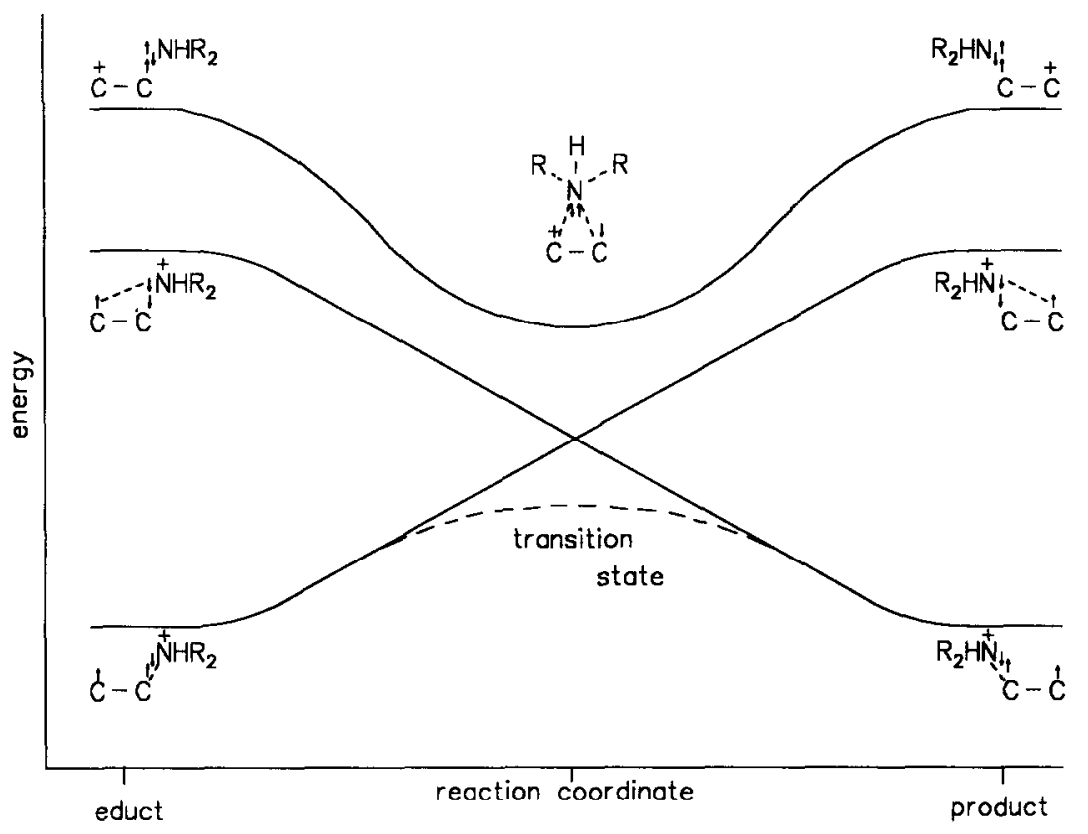

Fig. 4. Configuration mixing model for the rearrangement of an $\alpha$-distonic ammonium ion by a 1,2-shift of $\mathrm{NHR}_{2}\left(\mathrm{R}=\mathrm{H}, \mathrm{CH}_{3}\right)$.

ion. The second relevant state besides the ground state corresponds to a triplet state of the reactant in which the bonding electron pair is decoupled. This state is repulsive with respect to the $\mathrm{C}_{\alpha}-\mathrm{N}$ bond, and its initial energy depends on the strength of this bond. Furthermore, this state is bonding for the interaction between the electrons at $\mathrm{C}_{\beta}$ and $\mathrm{N}$, and its energy decreases along the reaction coordinate (the 1,2-shift of the $\mathrm{NR}_{3}$ group). Eventually this state becomes the ground state of the rearranged distonic ion. Thus, the activation energy for the $1,2-\mathrm{NR}_{3}$ shift within a $\beta$-distonic ammonium ion arises basically from an avoided crossing of these two states. However, there is another excited state of the educt distonic ion relevant for the rearrangement. In this state initially the electron at $\mathrm{C}_{\beta}$ is transferred to the $\mathrm{C}_{\alpha}-\mathrm{N}$ bond, and along the reaction coordinate the $\mathrm{NR}_{3}$ group migrates with a two-electron lone pair, while the positive charge is located at the carbon skeleton, resembling a heterolytic $\mathrm{C}_{\alpha}-\mathrm{N}$ bond cleavage. Therefore, this state looks like a $\pi$ complex of a neutral amine $\mathrm{NR}_{3}$ with an ionized $\mathrm{C}-\mathrm{C}$ double bond at the critical configuration of the system, and it has an energy minimum at this configuration. Thus the transition state of the $1,2-\mathrm{NR}_{3}$ shift is particularly stabilized by a resonance contribution of this state. This description of the rearrangement agrees with the result of an ab initio calculation of the transition state for the 1,2- $\mathrm{NH}_{3}$ shift in the $\beta$-distonic ion $\cdot \mathrm{CH}_{2}-\mathrm{CH}_{2}-\mathrm{NH}_{3}^{+}$[28], showing consider- 
able positive charge at the $\mathrm{C}$ atoms. The curve crossing model predicts a considerable influence of the $\operatorname{IE}\left(\mathrm{NR}_{3}\right)$ on the activation energy of the rearrangement owing to the participation of the additional excited state. The energy of this excited state, relative to the ground state of the initial $\beta$-distonic ion, depends on the difference of the IE of $\mathrm{NR}_{3}$ and the benzene derivative. For $\operatorname{IE}\left(\mathrm{NR}_{3}\right)>\mathrm{IE}$ (benzene), the charge distribution due to the additional cxcitcd state is cncrgetically favourable and the activation energy for a 1,2$\mathrm{NR}_{3}$ shift around the benzene ring should be decreased. In the case of $\mathrm{IE}\left(\mathrm{NR}_{3}\right)<\mathrm{IE}$ (benzene), however, a $\pi$ complex of a neutral amine and an ionized benzene is unfavourable, and this additional excited state will increase the activation energy of the $1,2-\mathrm{NR}_{3}$ shift.

The inversion of the effect of the additional state on the activation energy occurs in the series $\mathrm{NH}_{3}, \mathrm{CH}_{3} \mathrm{NH}_{2}$, and $\left(\mathrm{CH}_{3}\right)_{2} \mathrm{NH}$ because the $\mathrm{IE}\left(\mathrm{NH}_{3}\right)$ is larger and the $\operatorname{IE}\left(\left(\mathrm{CH}_{3}\right)_{2} \mathrm{NH}\right)$ is smaller than the IE(halobenzenes) studied. Thus, the reactions of $\left(\mathrm{CH}_{3}\right)_{2} \mathrm{NH}^{\cdot+}$ with neutral halobenzene are not only less exothermic than the reactions of $\mathrm{CH}_{3} \mathrm{NH}_{2}^{+}$, but should exhibit increased activation barriers for the rearrangement of the initially formed intermediate distonic ions into the reactive configuration. As a consequence these substitution reactions should have a small eff $_{\text {subst }}$ and a distinct effect of the relative orientations of two substituents at the benzene ring, but nevertheless a low $\mathrm{I} / \mathrm{Cl}$ selectivity in the case of the chloroiodobenzenes. Thus, the curve crossing model pictures the experimental results for the substitution reactions of halobenzenes and amines via radical cations and the dependence of this reaction on the structure of the reactants quite satisfactorily. It would be of interest, however, to complement these predictions and explanations by more elaborate quantitative calculations on a suitable model system.

\section{ACKNOWLEDGEMENT}

The FT-ICR spectrometer used for this study was granted by the Deutsche Forschungsgemeinschaft. The financial assistance of the Deutsche Forschungsgemeinschaft and additional assistance by the Fonds der Chemischen Industrie is gratefully acknowledged. D.T. thanks the Studienstiftung des Deutschen Volkes for a Doktorandenstipendium.

\section{REFERENCES}

1 (a) K. Yoshida, Electrooxidation in Organic Chemistry, Wiley, New York, 1984.

(b) M.A. Fox and M. Channon (Eds.), Photoinduced Electron Transfer, Elsevier, Amsterdam, 1988.

2 (a) D.J. Belleville and N.L. Bauld, J. Am. Chem. Soc., 104 (1982) 2665.

(b) N.L. Bauld, B. Harichian, D.W. Reynolds and J.C. White, J. Am. Chem. Soc., 110 (1988) 8111 . 
(c) N.L. Beald, D.J. Belleville, R. Pabon, R. Green and G. Chelsky, J. Am. Chem. Soc., 105 (1983) 2378.

(d) K. Chockaligam, M. Pinto and N.L. Bauld, J. Am. Chem. Soc., 112 (1990) 447.

3 N.L. Bauld and G.A. Mirafzal, J. Am. Chem. Soc., 113 (1991) 3513.

4 (a) A. Pross and S.S. Shaik, Acc. Chem. Res., 16 (1983) 363.

(b) S.S. Shaik, Prog. Phys. Org. Chem., 15 (1985) 197.

(c) S.S. Shaik and A. Pross. J. Am. Chem. Soc., 111 (1989) 4306.

(d) S.S. Shaik, Acta Chem. Scand., 44 (1990) 205.

(e) S.S. Shaik and E. Canadell, J. Am. Chem. Soc., 112 (1990) 1446.

5 A.J. Ferrer-Correira, K.R. Jennings and D.K. ShenSharma, Org. Mass Spectrom., 11 (1976) 867.

6 (a) G.S. Groenewold and M.L. Gross, in M.A. Almoster-Ferreira (Ed.), Ionic Processes in the Gas Phase, Reidel, Dordrecht, 1984, p. 243.

(b) G.S. Groenewold and M.L. Gross, J. Am. Chem. Soc., 106 (1984) 6569.

(c) G.S. Groenewold and M.L. Gross, J. Am. Chem. Soc., 106 (1984) 6575.

7 M.L. Gross and F.W. McLafferty, J. Am. Chem. Soc., 93 (1971) 1267.

8 T. Drewello, N. Heinrich, W.P.M. Maas, N.M.M. Nibbering, T. Weiske and H. Schwarz, J. Am. Chem. Soc., 109 (1987) 4810.

9 D. Thölmann, D. Flottmann and H.-Fr. Grützmacher, Chem. Ber., 124 (1991) 2349.

10 (a) D. Thölmann and H.-Fr. Grützmacher, J. Am. Chem. Soc., 113 (1991) 3281.

(b) D. Thölmann and H.-Fr. Grützmacher, Chem. Phys. Lett., 163 (1989) 225.

11 V.D. Parker, K.L. Handoo and B. Reitstöen, J. Am. Chem. Soc., 113 (1991) 6218.

12 For a discussion see ref. 10.

13 D. Thölmann and H.-Fr. Grützmacher, Org. Mass. Spectrom., 24 (1989) 439.

14 T. Su and W.J. Chesnavich, Chem. Phys., 76 (1982) 5183.

15 S.G. Lias, J.F. Liebman, J.L. Holmes, R.D.G. Mallard, J. Phys. Chem. Ref. Data, 17 (suppl. 1) (1988).

16 Organikum, (Autorenkollektiv Eds.), VEB Verlag der Wissenschaften, Berlin, 1986, p. 546.

17 M. Allemann, H.P. Kellerhals and K.P. Wanczek, Int. J. Mass Spectrom. Ion Phys., 46 (1983) 139.

18 P. Kofel, M. Allemann, H.P. Kellerhals and K.P. Wanczek, Int. J. Mass Spectrom. Ion Processes, 65 (1985) 97.

19 D. Smith and N.G. Adams, Int. J. Mass Spectrom. Ion Phys., 23 (1977) 123.

20 N.G. Adams, D. Smith and J.F. Paulson, J. Chem. Phys., 72 (1980) 288.

21 T.B. McMahon and J.L. Beauchamp, J. Phys. Chem., 81 (1977) 593.

22 J.E. Bartmess and R.M. Georgiadis, Vacuum, 33 (1983) 149.

23 (a) D.C. Clary, J. Chem. Soc., Faraday Trans. 2, 83 (1987) 139.

(b) K.J. Miller and J.A. Savchik, J. Am. Chem. Soc., 101 (1979) 7206.

(c) Landolt-Börnstein, Atom uind Molekularphysik, 6th edn., Vol. 1, Part 3, SpringerVerlag, Berlin, 1951.

(d) H.A. Stuart and H. Volkmann, Z. Phys., 80 (1933) 107.

(e) L.G. Groves, J. Chem. Soc., (1934) 1094.

(f) E.M. Moore and M.E. Hobbs, J. Am. Chem. Soc., 71 (1949) 411.

24 M.J.S. Dewar, E.G. Zoebisch, E.F. Healy and J.J.P. Stewart, J. Am. Chem. Soc., 107 (1985) 3902.

25 (a) M.J.S. Dewar and K.M. Dieter, J. Am. Chem. Soc., 108 (1986) 8075.

(b) D.M. Myton and R.J. O'Brien, Anal. Chem., 63 (1991) 1201. 
26 T.H. Lowry and K. Schueller Richardson, in Mechanism and Theory in Organic Chemistry, 3rd edn., Harper \& Row, New York, 1987.

27 (a) S. Hammerum, D. Kuck and P.J. Derrick, Tetrahedron Lett., 25 (1984) 4193.

(b) S. Hammerum, Org. Mass Spectrom., 20 (1985) 314.

28 (a) B.T. Golding and L. Radom, J. Am. Chem. Soc., 98 (1976) 6331.

(b) B.F. Yates and L. Radom, Org. Mass Spectrom., 22 (1987) 430. 